Piotr Klimczyk* (iD https://orcid.org/0000-0002-3137-4211

Państwowa Uczelnia im. Stefana Batorego

e-mail: pklimczyk@pusb.pl

\title{
Korzystanie z mediów społecznościowych, a ich wpływ na funkcjonowanie adolescentów i młodych dorosłych - zarys problemu
}

\begin{abstract}
Streszczenie: Celem artykułu było zaprezentowanie wybranych wniosków i zarysu badań dotyczących relacji między mediami społecznościowymi a adolescentami i młodymi dorosłymi. W pracy skupiono się na trzech aspektach z zakresu zainteresowań między innymi cyberpsychologii, takich jak kwestia różnic płciowych i wieku w sposobie korzystania z mediów społecznościowych, ich wpływ na kształtowanie się tożsamości oraz relacje między użytkownikiem, mediami społecznościowymi a samooceną. Przytoczone badania pokazują dynamikę zmian w sposobie korzystania z mediów społecznościowych w perspektywie płci, gdzie w początkach kształtowania się internetu to chłopcy korzystali z niego więcej w celu komunikowania się z innymi, a współcześnie relacja ta wygląda inaczej. Badania dotyczące tożsamości skupiają się na możliwości badania jej kształtowania i uwzględnienia pewnych specyficznych jej aspektów. Wnioski z badań poświęconych samoocenie są niekonkluzywne i w głównej mierze korelacyjne, przez to konieczne jest dalsze prowadzenie badań w tym obszarze.
\end{abstract}

Słowa kluczowe: cyberpsychologia, tożsamość, samoocena, media społecznościowe, adolescenci, młodzi dorośli

* Piotr Klimczyk - magister psychologii, asystent w Państwowej Uczelni im. Stefana Batorego. Praktyk, psycholog szkolny w Szkole Podstawowej nr 4 im. Marii Skłodowskiej-Curie w Skierniewicach. Zainteresowania badawcze skupiają się wokół problematyki psychologii narracyjnej, cyberpsychologii oraz psychologii wychowawczej. 


\section{Wstęp}

Media społecznościowe wymagają od użytkownika pełnej ekspresji związanej z własną osobą. Jest to w pewien sposób wpisane w ich założenia. Nie chodzi tylko o publikowanie treści pod własnym imieniem i nazwiskiem, dzięki którym inni użytkownicy i/lub znajomi offline mogą nas zlokalizować, ale też o przedstawianie swoich zainteresowań, najlepszych momentów z życia, liczby znajomych, którzy stają się wyznacznikiem popularności, swoich przemyśleń i komentarzy dotyczących innych osób. W ten sposób wszelkie dane na nasz temat stają się produktem, który można sprzedać, ale jest to konieczne, aby móc funkcjonować w tej cyfrowej rzeczywistości, której stałym elementem są właśnie social media ${ }^{1}$.

Ich istotność we współczesnym świecie widać również w zainteresowaniach nauk społecznych. Jedną z nich jest cyberpsychologia, będąca nauką z pogranicza psychologii i nowych mediów, która zajmuje się badaniem relacji między człowiekiem a jego obcowaniem z przestrzenią internetową, sferą komunikacji na odległość poprzez użycie internetu, wpływu gier wideo i kultury graczy na funkcjonowanie człowieka i wielu innych obszarów ${ }^{2}$. W prezentowanej pracy zostaną przedstawione wybrane wnioski i zarys badań nad relacją między użytkownikiem a portalami społecznościowymi, jej psychologiczne uwarunkowania i konsekwencje dla adolescentów i młodych dorosłych. Kryteria wiekowe (odpowiednio od 10. do 20.-23. roku życia oraz od 20.-23. do 35.-40. roku życia) przyjęto za Obuchowską ${ }^{3}$ i Gurbą ${ }^{4}$.

Skupiono się na trzech głównych obszarach: wieku i płci, budowaniu poczucia tożsamości oraz samoocenie. Sfery te stają się szczególnie znaczące w okresie dorastania i wczesnej dorosłości. Są też ze sobą wzajemnie powiązane. Fragment poświęcony wiekowi i płci ma na celu zobrazowanie, że to właśnie adolescenci oraz młodzi dorośli są głównymi użytkownikami mediów społecznościowych. Budowanie poczucia własnej tożsamości jest zadaniem rozwojowym stojącym przed adolescentem i młodym dorosłym, a jego realizacja może wpływać na poziom samooceny.

${ }^{1}$ Zob M. Walrave, S. Utz, A.P. Schouten, W. Heirman, Editorial: The state of online self-disclosure in an era of commodified privacy, "Cyberpsychology: Journal of Psychosocial Research on Cyberspace" 2016, No. 10(1).

2 Zob. A. Ogonowska, Cyberpsychologia. Nowe perspektywy badania mediów i ich użytkowników, „Annales Universitatis Paedagogicae Cracoviensis | Studia De Cultura” 2018, nr 10(4); A. Ogonowska, Edukacja medialna w kontekście cyberpsychologii. Nowe perspektywy badania mediów i ich użytkowników we wspótczesnej cywilizacji medialnej, „Interdyscyplinarne Konteksty Pedagogiki Specjalnej” 2018, nr 23; J. Pluta, Psychologiczne badania nad mediami - droga do powstania nowej dyscypliny, „Media i Społeczeństwo” 2019, nr 11.

${ }^{3}$ I. Obuchowska, Adolescencja, [w:] B. Harwas-Napierała, J. Trempała (red.), Psychologia rozwoju człowieka. Charakterystyka okresów życia człowieka, PWN, Warszawa 2007.

${ }^{4}$ E. Gurba, Wczesna dorosłość, [w:] B. Harwas-Napierała, J. Trempała (red.), Psychologia rozwoju człowieka. Charakterystyka okresów życia człowieka, PWN, Warszawa 2007. 


\section{Korzystanie z mediów społecznościowych, a wiek i płeć}

Badania skoncentrowane na psychologicznych korzyściach dla użytkowników mediów społecznościowych podkreślały możliwość komunikowania się i utrzymywania kontaktu z rówieśnikami. Jest to jeden z głównych motywów osób korzystających z social media. W badaniach Barker ${ }^{5}$ istotnym czynnikiem, który miał na to wpływ, było zadowolenie z grupy, która akceptowała badanego jako swojego członka. Osoby, które negatywnie oceniały swoich rówieśników i nie czuły się częścią grupy, poszukiwały w mediach społecznościowych osób spoza niej. W przypadku badanych, którzy cieszyli się z bycia jej członkiem, zależność ta była odwrotna. Płeć stanowiła zmienną różnicującą. Kobiety czerpały większą satysfakcję ze spędzania czasu w social mediach i przeznaczały na to generalnie więcej czasu niż mężczyźni. Znaczna część adolescentów zakłada konto w mediach społecznościowych ze względu na potrzeby socjalizacyjne, ale to dla dziewcząt aspekt wizualnego przedstawiania siebie, użytej formy artystycznej i estetyki zdjęcia profilowego były ważniejsze niż dla chłopców ${ }^{6}$. Różne aspekty i modalności w komunikacji mogą mieć znaczący wpływ na jakość relacji pomiędzy przyjaciółmi komunikującymi się poprzez internet ${ }^{7}$. Zależność ta może stanowić wytłumaczenie wspomnianej różnicy między płciami.

Z badań Joinera i jego zespołu ${ }^{8}$ wynika, że istnieje znacząca różnica między użytkownikami internetu urodzonymi po 1980 i po 1993 roku. Ci drudzy mieli bardziej pozytywny stosunek do internetu, dużo bardziej się z nim identyfikowali oraz przejawiali mniej niepokoju (anxiety) związanego z użytkowaniem internetu. Sitko-Dominik ${ }^{9}$ zaobserwowała podobną zależność - młodsze roczniki (18-23 lata) częściej niż starsze (24-35 lat) były bardziej obecne internetowo, miały więcej znajomych i częściej korzystały z Facebooka w celach towarzyskich, zaspokajając w ten sposób potrzebę afiliacji ${ }^{10}$. Starszym badanym Facebook służył w głównej mierze do zyskiwania popularności, romantycznych związków oraz do gier.

${ }^{5} \mathrm{~V}$. Barker, Older adolescents' motivations for social network use: the influence of gender, group identity, and collective self-esteem, "CyberPsychology \& Behavior" 2009, No. 12(2).

${ }^{6}$ A. Siibak, Constructing the Self through the Photo selection - Visual Impression Management on Social Networking Websites, "Cyberpsychology: Journal of Psychosocial Research on Cyberspace" 2009, No. 3(1).

7 Zob. L.E. Sherman, M. Michikyan, P.M. Greenfield, The effects of text, audio, video, and in-person communication on bonding between friends, "Cyberpsychology: Journal of Psychosocial Research on Cyberspace" 2013, No. 7(2).

${ }^{8}$ R. Joiner, J. Gavin, M. Brosnan, J. Cromby, H. Gregory, J. Guiller, P. Maras, A. Moon, Comparing First and Second Generation Digital Natives' Internet Use, Internet Anxiety, and Internet Identification, "Cyberpsychology, Behavior, and Social Networking" 2013, No. 16(7).

${ }^{9}$ M. Sitko-Dominik, Przynależność generacyjna, płeć psychologiczna, postawy wobec miłości a style użytkowania Facebooka przez młodych dorosłych, „Polskie Forum Psychologiczne” 2020, nr 25(2).

${ }_{10}$ Z. Wang, J.M. Tchernev, T. Solloway, A dynamic longitudinal examination of social media use, needs, and gratifications among college students, "Computers in Human Behavior" 2012, No. 28(5), cyt. za: M. Sitko-Dominik, dz. cyt. 
Potoczny wniosek, że to dziewczęta korzystają częściej z mediów społecznościowych wydaje się dzisiaj dla wielu osób naturalny, jednak dane uzyskane na przestrzeni ostatnich dwóch dekad pokazują znaczącą dynamikę tego procesu. Z badań Joinera i współpracowników ${ }^{11}$ wynika, że dziewczęta nie były chętne do korzystania $\mathrm{z}$ internetowych metod komunikacji. Jednocześnie chłopcy, którzy budowali swoją tożsamość wokół internetu, byli nazywani pejoratywnie geekami ${ }^{12}$ lub nerdami. Na przestrzeni kilku lat zależność ta uległa znacznej zmianie, ponieważ w 2012 roku ${ }^{13}$ kobiety przejawiały dużo większe zainteresowanie aspektem komunikacyjnym w internecie i korzystały więcej z mediów społecznościowych niż mężczyźni.

\section{Kształtowanie i prezentowanie tożsamości w przestrzeni internetowej}

Psychologiczne korzyści, które niosą ze sobą wirtualne znajomości, zostały zaobserwowane na długo przed pojawieniem się mediów społecznościowych w takiej postaci, w jakiej znamy je dzisiaj. Thomas ${ }^{14}$ obserwował i badał interakcje dzieci korzystających ze specjalnego czatu internetowego, w którym każdy mógł stworzyć własnego awatara, czyli swoją wykreowaną, cyfrową reprezentację. Z jego obserwacji wynika, że dzieci i nastolatki (w wieku od 8 do 16 lat) w sposób spontaniczny wchodziły w rolę nauczyciela, odpowiadając na zadawane przez innych pytania lub próbowały rozwiązać wspólnie dany problem przy braku wyraźnej roli eksperta u jednego z nich. $\mathrm{W}$ wywiadach podkreślały, że łatwiej jest im nawiązać relacje $\mathrm{z}$ obcą osobą w internecie, ponieważ nie jest to dla nich tak straszne jak w prawdziwym życiu. Istotna z punktu widzenia rozważań tej pracy była też kwestia tożsamości - dzieci dowolnie mogły ją kreować, wybierać i odrzucać, będąc na przykład kimś bardziej asertywnym w zależności od tego, w jakiej grupie się aktualnie znajdowały.

Korzystanie z mediów społecznościowych jest dla adolescenta możliwością spełnienia potrzeb związanych z kreowaniem tożsamości. Jest to możliwe w dużej mierze poprzez publikowanie tak zwanych selfie, czyli zdjęć przedstawiających własną twarz lub siebie w odbiciu lustra. Ujęcie psychospołeczne zakłada, że na tym etapie rozwoju u ado-

${ }^{11}$ R. Joiner, J. Gavin, M. Brosnan, C. Crook, J. Duffield, A. Durndell, J. Guiller, P. Maras, A.J. Scott, Internet identification and future internet use, "CyberPsychology \& Behavior" 2006, No. 9(4).

${ }^{12}$ G. Valentine, S. Holloway, "Technophobia": parents and children's fears about information and communication technologies and the transformation of culture and society, [w:] I. Hutchby, J. Moran-Ellis (red.), Children, technology and culture: the impacts of technologies in children's everyday lives, Routledge, Londyn 2001.

${ }^{13}$ R. Joiner, J. Gavin, M. Brosnan, J. Cromby, H. Gregory, J. Guiller, P. Maras, A. Moon, Gender, Internet Experience, Internet Identification, and Internet Anxiety: A Ten-Year Followup, "Cyberpsychology, Behavior, and Social Networking" 2012, No. 15(7).

${ }^{14}$ A. Thomas, Textual constructions of children's online identities, "CyberPsychology \& Behavior" 2000, No. 3(4). 
lescenta dochodzi do eksplorowania, szukania znaczeń i wyjaśnień dla własnego poczucia tożsamości. Percepcja związana z postrzeganiem i ocenianiem na przykład własnego ciała jest bardzo krucha i niepewna. Jednego dnia można je oceniać jako zadowalające, następnego - nie móc na nie patrzeć w lustrze. Ta kruchość i niepewność jest naturalnym elementem tego okresu rozwoju, co przejawia się między innymi w częstych zmianach, czasami radykalnych, dotyczących własnego wyglądu lub wyznawanych poglądów ${ }^{15}$.

Steijn ${ }^{16}$ porównał, bazując na podejściu rozwojowym związanym z potrzebą budowania tożsamości i sieci relacji społecznych, trzy grupy użytkowników mediów społecznościowych: adolescentów, młodych dorosłych oraz dorosłych. Założył, że przestrzeń internetowa jest innym rodzajem środowiska, w którym można obserwować poznane już zależności dotyczące potrzeby kontaktów społecznych u nastolatków oraz dynamiki tworzenia przez nich własnej tożsamości. Wnioski okazały się spójne z przytoczonymi przez niego koncepcjami - adolescenci mieli więcej internetowych znajomych oraz częściej dodawali nieznane osoby do tego grona. Młodzi dorośli prezentowali dużo mniej informacji publicznie, skupieni byli na podtrzymywaniu już posiadanych znajomości i częściej konfigurowali ustawienia prywatności swojego konta w porównaniu z pozostałymi grupami.

Przez możliwość kontroli tego, jak ma wyglądać nasza internetowa tożsamość, istnieje ryzyko pokusy przedstawienia siebie w nieprawdziwym świetle, budowania sztucznej reprezentacji siebie w przestrzeni internetowej ${ }^{17}$. Nie znaczy to jednak, że jedynym motywem, stojącym za takim sposobem prezentacji jest chęć przypisania sobie pewnych atrybutów, których w rzeczywistości nie posiadamy. Autoprezentacja dokonana w sieci może być oderwana od rzeczywistej cielesności, statusu społecznego, posiadanych dóbr ${ }^{18}$. Dla osób ukrywających przed otoczeniem pewne cechy lub zachowania, które mogą narazić je na ostracyzm (na przykład fetysze seksualne, afiliacje ze skrajnymi grupami politycznymi), internet stanowi możliwość zaakceptowania, przez siebie, tych cech dzięki przyjmowaniu do grona internetowych znajomych osób, które współdzielą te cechy. Stanowi to dla nich źródło akceptacji dla własnych poglądów i przymiotów ${ }^{19}$. Kreowanie swojej tożsamości w internecie może być formą

15 I. Obuchowska, dz. cyt.

${ }_{16}$ W.M. Steijn, A developmental perspective regarding the behaviour of adolescents, young adults, and adults on social network sites, "Cyberpsychology: Journal of Psychosocial Research on Cyberspace" 2014, No. 8(2).

17 O. Gil-Or, Y. Levi-Belz, O. Turel, The "Facebook-self": characteristics and psychological predictors of false self-presentation on Facebook, "Frontiers in Psychology" 2016, No. 6.

${ }_{18}$ M. Trusewicz-Pasikowska, Tożsamość wirtualna - droga do wyzwolenia czy zniewolenia?, [w:] A. Kampka, K. Masłowska, A. Pawłowska (red.), Co nas wyzwala, co nas zniewala? Młodzi o wolności, Wydawnictwo SGGW, Warszawa 2018.

19 K.Y.A. McKenna, J.A. Bargh, Coming out in the age of the Internet: Identity "demarginalization" through virtual group participation, "Journal of Personality and Social Psychology" 1998, No. 75(3), cyt. za: K.Y.A. McKenna, A. Green, P. Smith, Demarginalizing the sexual self, "Journal of Sex Research” 2001, No. 38(4). 
autoprezentacji, która przybiera czasami paradoksalne formy, takie jak zamieszczanie jako zdjęcia profilowego fotografii zwierzęcia, rośliny czy postaci z serialu. Ma to być forma budowania dystansu, ale dobór tych postaci i rzeczy nie jest przypadkowy i może komunikować coś osobie oglądającej ten profil. Częste zamieszczanie powtarzających się elementów, na przykład zdjęć ze zwierzętami, może być też formą sprawiania pozoru i chęci pokazania się jako osoby wrażliwej. Nie bez znaczenia jest też rodzaj medium społecznego - w przypadku blogów oczekuje się raczej przedstawienia siebie w formie jak najbardziej autentycznej, natomiast w portalach społecznościowych użytkownicy czują, że potrzebują zaprezentować się z jak najlepszej strony ${ }^{20}$.

Kształtowanie się tożsamości pozostaje od dekad w centrum zainteresowania badaczy reprezentujących różne nauki społeczne ${ }^{21}$. Wydaje się, że naturalnym kierunkiem rozwoju tej problematyki jest badanie relacji między korzystaniem z mediów społecznościowych a procesami składającymi się na budowanie poczucia własnej tożsamości przez adolescentów i młodych dorosłych. Noon ${ }^{22}$, opierając się na trójczynnikowym modelu rozwoju tożsamości ${ }^{23}$, spróbował przyjrzeć się tej relacji. Model, który stanowił teoretyczne zaplecze badania, zakłada, że tożsamość jest kształtowana i modyfikowana przez wzajemnie powiązane trzy procesy: zaangażowanie (commitment), dogłębną eksplorację (in-depth exploration) oraz rewizję zaangażowania (reconsideration of commitment). Zaangażowanie jest tu rozumiane jako trwanie w wyborach, które osoba podejmuje w różnych sferach życia, będące źródłem jej pewności siebie. W przypadku kiedy dokonane wybory przestają być źródłem pewności siebie, pojawia się niepewność i poczucie niewłaściwej alokacji zasobów i własnego potencjału. Dochodzi wtedy do ich porzucenia i dalszego poszukiwania. Autor przeprowadził badanie z użyciem aplikacji Instagram, która stanowi źródło porównań społecznych wśród adolescentów - co w myśl trójczynnikowego modelu rozwoju tożsamości może pro-

${ }^{20}$ M. Gliniecka, Profil na Facebooku - awatar, wirtualna maska czy obraz siebie? O konstruowaniu tożsamości internetowej, „Zarządzanie Mediami” 2017, nr 5(2).

${ }^{21}$ Zob. E.J. Marcia, Development and validation of ego-identity status, "Journal of Personality and Social Psychology" 1960, No. 3(5); E.J. Marcia, Identity in Adolescent, [w:] J. Adelson (red.), Handbook of Adolescent Psychology, Wiley, Nowy Jork 1980; E.J. Marcia, Identity and Psychosocial Development in Adulthood, "Identity: An International Journal of Theory and Research" 2002, No. 2(1); E. Erikson, Tożsamość a cykl życia, Wydawnictwo Zysk i S-ka, Poznań 2004; K. Luyckx, B. Soenens, D.M. Berzonsky, I. Smits, L. Goossens, M. Vansteenkiste, Information-oriented identity processing, identity consolidation, and well-being: the moderating role of autonomy, self-reflection, and self-rumination, "Personality and Individual Differences" 2007, No. 43; K. Jespersen, J. Kroger, M. Martinussen, Identity status and ego development: a meta-analysis, "Identity: An International Journal of Theory and Research" 2013, No. 13.

${ }^{22}$ E.J. Noon, Compare and despair or compare and explore? Instagram social comparisons of ability and opinion predict adolescent identity development, "Cyberpsychology: Journal of Psychosocial Research on Cyberspace" 2020, No. 14(2).

${ }^{23}$ E. Crocetti, M. Rubini, W.H.J. Meesus, Capturing the dynamics of identity formation in various ethnic groups: Development and validation of a three-dimensional model, "Journal of Adolescence" 2008, No. 31(2), cyt. za: tamże. 
wadzić do zmian eksploracyjnych dotyczących tożsamości. Wyniki badania sugerują, że porównywanie własnych zdolności i posiadanych opinii może mieć istotny wpływ na rozwój tożsamości adolescenta. Nastoletni chłopcy biorący udział w badaniu byli mniej narażeni na negatywne skutki porównań społecznych dotyczących posiadanych zdolności na Instagramie. Wniosek ten autor opiera na negatywnej korelacji między porównaniem społecznym a czynnikiem rewizji zaangażowania, co może być rozumiane jako utwierdzenie we własnych wyborach. Jednak zależność ta dotyczyła osób, które generalnie nie posiadały jasno wyklarowanej tożsamości. Noon teoretyzuje, że w przypadku nastolatków, którzy mają silne poczucie tego, kim są, jakie wartości są dla nich ważne i czego ich zdaniem oczekuje od nich społeczeństwo, mogą być bardziej wrażliwi na wyłapywanie subiektywnych niedoskonałości. Nie bez znaczenia pozostaje również to, do kogo porównują siebie w mediach społecznościowych.

Innym, równie istotnym czynnikiem, który wpływa na prezentowanie siebie przez użytkowników mediów społecznościowych, jest legitymowanie lub potępianie pewnych zachowań przez dyskurs panujący w nastoletnich grupach. Mascheroni, Vincent i Jimenez ${ }^{24}$ przeprowadzili serię wywiadów z nastolatkami (11-16 lat) pochodzącymi z trzech różnych krajów (Włochy, Wielka Brytania i Hiszpania) na temat zdjęć publikowanych na Facebooku. Z ich badania wynika, że wśród nastolatków panują podwójne standardy dotyczące sfery seksualnej ze względu na płeć. Dziewczęta odczuwają silniejszą presję związaną z podkreślaniem swojej atrakcyjności, a ich dwuznaczne pozy, prezentowane na zdjęciach, mają być potwierdzeniem stereotypowych zachowań, które spotykają się z akceptacją ze strony rówieśników. Chłopcy oceniali bardzo krytycznie takie zdjęcia, uznając je za tanie próby zdobycia popularności lub bycia „pewnym rodzajem dziewczyny”, sugerując seksualną swobodę tych dziewcząt.

Powyższe wnioski łączą się z koncepcją samooceny, która w okresie dorastania i poszukiwania tożsamości może być szczególnie narażona na wahania. Relacja między samooceną a korzystaniem z mediów społecznościowych była częstym tematem badań w tym obszarze.

\section{Korzystanie z mediów społecznościowych a samoocena}

Wyniki badań sugerują, że subiektywnie postrzegana własna atrakcyjność fizyczna ma największy wpływ na globalną samoocenę adolescentów. Zależność ta jest szczególnie istotna w przypadku dziewczą ${ }^{25}$. Współcześni nastolatkowie coraz bardziej

${ }^{24}$ G. Mascheroni, J. Vincent, E. Jimenez, "Girls are addicted to likes so they post semi-naked selfies": Peer mediation, normativity and the construction of identity online, "Cyberpsychology: Journal of Psychosocial Research on Cyberspace" 2015, No. 9(1).

${ }_{25}$ T. von Soest, L. Wichstrøm, I.L. Kvalem, The development of global and domain-specific self-esteem from age 13 to 31, "Journal of Personality and Social Psychology" 2016, No. 110(4); L. Wichstrøm, T. von Soest, Reciprocal relations between body satisfaction and self-esteem: A large 13-year prospective study of adolescents, "Journal of Adolescence" 2016, No. 47. 
polegają na zdjęciach i filmach zamieszczanych w mediach społecznościowych, które stają się głównym sposobem autoprezentacji ${ }^{26}$. Jak już wspomniano, użytkownicy mediów społecznościowych zdają sobie sprawę z pewnego ogólnie pojętego wymogu przedstawiania siebie korzystnie w internecie. Prezentacja swojego wizerunku, na przykład poprzez selfie, ma służyć maksymalizacji atrakcyjności ${ }^{27}$.

Badania na temat relacji między publikowaniem selfie a samooceną są niekonkluzywne. Burrow i Rainone ${ }^{28}$ przyjrzeli się relacji między otrzymywaniem polubień pod zdjęciami na portalu Facebook a samooceną. Przeprowadzili w tym celu dwa badania - pierwsze dotyczyło współwystępowania polubień z samooceną badanego, drugie zakładało eksperymentalne manipulowanie liczbą polubień na facebookopodobnej stronie pod zdjęciami badanych i mierzenia ich poziomu samooceny. W obu tych badaniach zanotowano pozytywną korelację między liczbą polubień a wysokością samooceny. Czynnikiem modulującym tę zależność było poczucie celowości własnego życia. Ci spośród badanych, którzy mieli poczucie, że ich życie ma sens, nie uzależniali swojej samooceny od liczby polubień. Podobne wnioski uzyskali Gonzales i Hancock ${ }^{29}$, którzy sugerują, że użytkownicy mediów społecznościowych mają tendencję do selekcji informacji (głównie tych pozytywnych na swój temat), które zawierają w swoich profilach, a które po późniejszym przeglądaniu powodują wzrost ich samooceny.

Zależność między samooceną a korzystaniem z internetu była też celem badania Śliwaka i współpracowników ${ }^{30}$. Dotyczyło ono różnych form korzystania $z$ internetu (między innymi korzystania z portali społecznościowych) oraz samooceny w rozbiciu na jej składowe: kompetencje, bycie kochanym, popularność, zdolności przywódcze, samokontrola, samoakceptacja moralna, atrakcyjność fizyczna, witalność, integracja tożsamości, obronne wzmacnianie samooceny. W badaniu wzięły udział osoby w wieku 25-55 lat. Uzyskane wyniki nie wykazały zależności między ogólnym poziomem samooceny a częstotliwością korzystania z sieci, natomiast w przypadku konkretnych komponentów (zdolności przywódcze, obronne wzmacnianie samooceny i samokontrola) zależność ta była istotna statystycznie. Według autorów wyniki te sugerują, że osoby poświęcające dużo czasu w ciągu dnia na korzystanie z internetu wyżej oceniają własne zdolności kierowania innymi i mają wyższą potrzebę akceptacji społecznej.

${ }^{26}$ T.H.H. Chua, L. Chang, Follow me and like my beautiful selfies: Singapore teenage girls' engagement in self-presentation and peer comparison on social media, "Computers in Human Behavior" 2016, No. 55.

${ }^{27}$ J.C. Yau, S.M. Reich, "It's Just a Lot of Work": Adolescents' Self-Presentation Norms and Practices on Facebook and Instagram, "Journal of Research on Adolescence" 2018, No. 29(1).

${ }^{28}$ L.A. Burrow, N. Rainone, How many likes did I get?: Purpose moderates links between positive social media feedback and self-esteem, "Journal of Experimental Social Psychology" 2017, No. 69.

29 A.L. Gonzales, J.T. Hancock, Mirror, Mirror on my Facebook Wall: Effects of Exposure to Facebook on Self-Esteem, "Cyberpsychology, Behavior, and Social Networking" 2011, No. 14(1-2).

30 J. Śliwak, D. Zarosińska, M. Wysocka, J. Partyka, Poziom samooceny u osób korzystających z różnych form internetu, „Studia Socialia Cracoviensia” 2017, nr 9(2). 
Wraz ze wzrostem czasu spędzanego w sieci spada samokontrola badanych. Autorzy zależność tę wyjaśniają specyfiką internetu, który daje każdemu możliwość wyrażania własnych opinii i poglądów, pozwala wyrazić siebie, komentować wypowiedzi innych osób. Czynności te mogą wzmacniać ocenę własnych zdolności przywódczych, tworząc wrażenie, że wpływa się na sposób myślenia i postępowanie innych. Z drugiej strony osoby z wysoką potrzebą aprobaty społecznej mogą w internecie szukać różnych form aktywności, które pozwolą im uciec od własnych problemów w celu poprawy własnej samooceny, co w pewien sposób potwierdziły badania na grupie południowokoreańskich studentek ${ }^{31}$. Osoby z niższą potrzebą popularności odczuwały większe korzyści z publikowania selfie - czuły mniejszą dyssatysfakcję z obrazu własnego ciała, co przekładało się na ich wyższą samoocenę. Według autorki osoby posiadające wyższą potrzebę popularności są dużo bardziej wrażliwe i skupione na tym, co inne osoby piszą na ich temat, przez co efekt nawet pozytywnego feedbacku może nie mieć aż tak silnego skutku jak u osób, u których te potrzeby są niskie.

Pasywne przeglądanie mediów społecznościowych koreluje z obniżonym dobrostanem - poprzez porównywanie się z innymi użytkownikami, publikowanymi treściami, zdjęciami lub udziałem w różnych wydarzeniach spada jego subiektywne poczucie $^{32}$. W badaniu studentów ${ }^{33}$ wykazano, że bierne korzystanie z social mediów współwystępuje z dokonywaniem częstszych porównań społecznych, które z kolei związane są z FoMO (fear of missing out - strach przed przeoczeniem na przykład ważnej informacji, wydarzenia społecznego itp. ${ }^{34}$ ). Czynniki te stanowiły predyktor wystąpienia nasilonych symptomów depresji, spadku globalnej samooceny, subiektywnego poczucia własnej atrakcyjności fizycznej oraz poczucia bycia osobą atrakcyjną społecznie. Zależność ta była istotniejsza w przypadku kobiet. Przeglądy badańn ${ }^{35}$ sugerują, że w przypadku dzieci i młodych dorosłych istotną zmienną, która negatywnie wpływa na ich samoocenę i dobrostan jest cyberbullying, czyli prześladowanie i przemoc w internecie. Drugą zmienną jest depresja facebookowa (Facebook depression). Termin ten w 2011 roku zaproponowali O’Keefe i Clarke-Pearson ${ }^{36}$ w artykule

${ }^{31} \mathrm{M}$. Kim, Instagram selfie-posting and young women's body dissatisfaction: Investigating the role of self-esteem and need for popularity, "Cyberpsychology: Journal of Psychosocial Research on Cyberspace" 2020, No. 14(4).

32 P. Verduyn, O. Ybarra, M. Résibois, J. Jonides, E. Kross, Do Social Network Sites Enhance or Undermine Subjective Well-Being? A Critical Review, "Social Issues and Policy Review" 2017, No. 11(1).

${ }^{33}$ K. Burnell, M.J. George, J.W. Vollet, S.E. Ehrenreich, M.K. Underwood, Passive social networking site use and well-being: The mediating roles of social comparison and the fear of missing out, "Cyberpsychology: Journal of Psychosocial Research on Cyberspace" 2019, No. 13(3).

${ }^{34}$ Zob. B. Classen, J.K. Wood, P. Davies, Social network sites, fear of missing out, and psychosocial correlates, "Cyberpsychology: Journal of Psychosocial Research on Cyberspace" 2020, No. 14(3).

${ }_{35}$ Zob. D. Richards, H.P. Caldwell, H. Go, Impact of social media on the health of children and young people, "Journal of Paediatrics and Child Health" 2015, No. 51.

${ }^{36}$ S.G. O'Keefle, K. Clarke-Pearson, The impact of social media on children, adolescents, and families, "Council on Communications and Media Pediatrics" 2011, No. 127(4). 
na temat wpływu mediów społecznościowych na dzieci, adolescentów i ich rodziny. Późniejsze badania ${ }^{37}$ podkreślały jednak, że związek między depresją a mediami społecznościowymi istnieje, ale potrzeba więcej badań w celu określenia charakteru domniemanej przyczynowości.

Występowanie tak różnych stanowisk w tej sprawie komplikuje ich odniesienie do praktyki, tym bardziej że badania te często były korelacyjne, a przy jakościowym modelu pomijały zgodność ekologiczną badania - odbywały się w oderwaniu od właściwego środowiska, w którym obserwujemy dany fenomen (na przykład konkretną aplikację społecznościową). Ogden i Coulthard ${ }^{38}$ podjęły próbę wypełnienia tej luki $\mathrm{w}$ wiedzy na temat selfie. Bazując na dostępnych badaniach na temat zamieszczania selfie, otrzymywania za nie polubień (tzw. likeów) i ich wpływu na samoocenę zaprojektowały eksperyment $\mathrm{z}$ użyciem aplikacji społecznościowej Instagram. Badanych podzielono na trzy grupy, które przez tydzień musiały publikować zdjęcia z możliwością komentowania, publikować zdjęcia bez takiej możliwości oraz powstrzymać się od jakiegokolwiek udostępniania zdjęć. Wnioski zaskoczyły badaczki - nie odnotowano wpływu na samoocenę ani na nastrój. Było to sprzeczne z tym, na co wskazywały inne badania ${ }^{39}$. Zanotowano natomiast wpływ na zadowolenie $z$ wyglądu i zadowolenie z wyglądu twarzy. Te osoby, które przez tydzień nie publikowały selfie, wykazywały większą satysfakcję z wyglądu w porównaniu z pozostałymi dwiema grupami. I mimo że odnotowano wyższą satysfakcję z wyglądu własnej twarzy w wariancie publikowania zdjęć, to wzrost ten zanikał po tygodniu. Badaczki podkreślają jednak konieczność dalszego badania tego zjawiska. Zanotowano, co prawda, w eksperymencie inne zależności niż w większości korelacyjnych badań, ale badana próba nie była duża $(n=59)$, co utrudnia uogólnianie wyników. Być może należałoby również przyjąć perspektywę badań podłużnych.

\section{Podsumowanie}

Celem artykułu było przedstawienie pewnego zarysu problemu związanego z badaniami nad psychologicznymi konsekwencjami dla użytkowników mediów społecznościowych. Obserwuje się ciągły wzrost liczby dzieci, młodzieży, ale i dorosłych, korzystających z nich każdego dnia. Bardzo ważne jest zatem dokładne prześledzenie, w jaki sposób media te wpływają na funkcjonowanie użytkowników zarówno w przestrzeni internetowej, jak i poza sferą wirtualną.

${ }^{37}$ I. Pantic, A. Damjanovic, J. Todorovic, D. Topalovic, D. Bojovic-Jovic, S. Ristic, S. Pantic, Association between online social networking and depression in high school students: behavioral physiology viewpoint, "Psychiatria Danubina" 2012, No. 24(1).

${ }^{38} \mathrm{~N}$. Coulthard, J. Ogden, The impact of posting selfies and gaining feedback ('likes') on the psychological wellbeing of 16-25 year olds: an experimental study, "Cyberpsychology: Journal of Psychosocial Research on Cyberspace" 2018, No. 12(2).

${ }^{39}$ A.L. Gonzales, J.T. Hancock, dz. cyt.; L.A. Burrow, N. Rainone, dz. cyt. 
Wiedza na temat wyników przytoczonych badań może pomóc lepiej zrozumieć ich ważność szczególnie dla adolescentów, których zadaniem rozwojowym jest znalezienie odpowiedzi na pytanie, kim jestem, oraz nawiązanie szerokiej sieci społecznego wsparcia i relacji koleżeńskich. Świat wirtualny rządzi się innymi prawami niż świat rzeczywisty, ale, jak pokazują badania, relacje interpersonalne ze świata rzeczywistego przenikają do świata wirtualnego wraz z potrzebami, które należy zaspokoić na danym etapie rozwojowym. Mając to na uwadze, powinno się podchodzić w bardziej konstruktywny sposób do problematyki mediów społecznościowych i widzieć w nich coś więcej niż tylko sposób spędzania wolnego czasu.

\section{Bibliografia}

Barker V., Older adolescents' motivations for social network use: the influence of gender, group identity, and collective self-esteem, "CyberPsychology \& Behavior" 2009, No. 12(2).

Burnell K., George M.J., Vollet J.W., Ehrenreich S.E., Underwood M.K., Passive social networking site use and well-being: The mediating roles of social comparison and the fear of missing out, "Cyberpsychology: Journal of Psychosocial Research on Cyberspace" 2019, No. 13(3).

Burrow L.A., Rainone N., How many likes did I get?: Purpose moderates links between positive social media feedback and self-esteem, "Journal of Experimental Social Psychology" 2017, No. 69.

Chua T.H.H., Chang L., Follow me and like my beautiful selfies: Singapore teenage girls' engagement in self-presentation and peer comparison on social media, "Computers in Human Behavior” 2016, No. 55.

Classen B., Wood J.K., Davies P., Social network sites, fear of missing out, and psychosocial correlates, "Cyberpsychology: Journal of Psychosocial Research on Cyberspace" 2020, No. 14(3).

Coulthard N., Ogden J., The impact of posting selfies and gaining feedback ('likes') on the psychological wellbeing of 16-25 year olds: an experimental study, "Cyberpsychology: Journal of Psychosocial Research on Cyberspace” 2018, No. 12(2).

Crocetti E., Rubini M., Meesus W.H.J., Capturing the dynamics of identity formation in various ethnic groups: Development and validation of a three-dimensional model, "Journal of Adolescence" 2008, No. 31(2).

Erikson E., Tożsamość a cykl życia, Wydawnictwo Zysk i S-ka, Poznań 2004.

Gil-Or O., Levi-Belz Y., Turel O., The "Facebook-self": characteristics and psychological predictors of false self-presentation on Facebook, "Frontiers in Psychology" 2016, No. 6. 
Gliniecka M., Profil na Facebooku - awatar, wirtualna maska czy obraz siebie? O konstruowaniu tożsamości internetowej, „Zarządzanie Mediami” 2017, nr 5(2).

Gonzales A.L., Hancock J.T., Mirror, Mirror on my Facebook Wall: Effects of Exposure to Facebook on Self-Esteem, "Cyberpsychology, Behavior, and Social Networking" 2011, No. 14(1-2).

Gurba E., Wczesna dorosłość, [w:] B. Harwas-Napierała, J. Trempała (red.), Psychologia rozwoju człowieka. Charakterystyka okresów życia człowieka, PWN, Warszawa 2007.

Jespersen K., Kroger J., Martinussen M., Identity status and ego development: a meta-analysis, "Identity: An International Journal of Theory and Research" 2013, No. 13.

Joiner R., Gavin J., Brosnan M., Cromby J., Gregory H., Guiller J., Maras P., Moon A., Gender, Internet Experience, Internet Identification, and Internet Anxiety: A Ten-Year Followup, "Cyberpsychology, Behavior, and Social Networking" 2012, No. 15(7).

Joiner R., Gavin J., Brosnan M., Cromby J., Gregory H., Guiller J., Maras P., Moon A., Comparing First and Second Generation Digital Natives' Internet Use, Internet Anxiety, and Internet Identification, "Cyberpsychology, Behavior, and Social Networking" 2013, No. 16(7).

Joiner R., Gavin J., Brosnan M., Crook C., Duffield J., Durndell A., Guiller J., Maras P., Scott A.J., Internet identification and future internet use, "CyberPsychology \& Behavior" 2006, No. 9(4).

Kim M., Instagram selfie-posting and young women's body dissatisfaction: Investigating the role of self-esteem and need for popularity, "Cyberpsychology: Journal of Psychosocial Research on Cyberspace" 2020, No. 14(4).

Luyckx K., Soenens B., Berzonsky D.M., Smits I., Goossens L., Vansteenkiste M., Information-oriented identity processing, identity consolidation, and well-being: the moderating role of autonomy, self-reflection, and self-rumination, "Personality and Individual Differences" 2007, No. 43.

Marcia E.J., Development and validation of ego-identity status, "Journal of Personality and Social Psychology" 1960, No. 3(5).

Marcia E.J., Identity and Psychosocial Development in Adulthood, "Identity: An International Journal of Theory and Research" 2002, No. 2(1).

Marcia E.J., Identity in Adolescent, [w:] J. Adelson (red.), Handbook of Adolescent Psychology, Wiley, Nowy Jork 1980.

Mascheroni G., Vincent J., Jimenez E., "Girls are addicted to likes so they post semi-naked selfies": Peer mediation, normativity and the construction of identity online, "Cyberpsychology: Journal of Psychosocial Research on Cyberspace" 2015, No. 9(1).

McKenna K.Y.A., Bargh J.A., Coming out in the age of the Internet: Identity "demarginalization" through virtual group participation, "Journal of Personality and Social Psychology" 1998, No. 75(3). 
McKenna K.Y.A., Green A., Smith P., Demarginalizing the sexual self, "Journal of Sex Research" 2001, No. 38(4).

Noon E.J., Compare and despair or compare and explore? Instagram social comparisons of ability and opinion predict adolescent identity development, "Cyberpsychology: Journal of Psychosocial Research on Cyberspace” 2020, No. 14(2).

O'Keefle S.G., Clarke-Pearson K., The impact of social media on children, adolescents, and families, "Council on Communications and Media Pediatrics" 2011, No. 127(4).

Obuchowska I., Adolescencja, [w:] B. Harwas-Napierała, J. Trempała (red.), Psychologia rozwoju człowieka. Charakterystyka okresów życia człowieka, PWN, Warszawa 2007.

Ogonowska A., Cyberpsychologia. Nowe perspektywy badania mediów i ich użytkowników, „Annales Universitatis Paedagogicae Cracoviensis | Studia De Cultura” 2018, nr 10(4).

Ogonowska A., Edukacja medialna w kontekście cyberpsychologii. Nowe perspektywy badania mediów i ich użytkowników we współczesnej cywilizacji medialnej, „Interdyscyplinarne Konteksty Pedagogiki Specjalnej” 2018, nr 23.

Pantic I., Damjanovic A., Todorovic J., Topalovic D., Bojovic-Jovic D., Ristic S., Pantic S., Association between online social networking and depression in high school students: behavioral physiology viewpoint, "Psychiatria Danubina" 2012, No. 24(1).

Pluta J., Psychologiczne badania nad mediami - droga do powstania nowej dyscypliny, „Media i Społeczeństwo” 2019, nr 11.

Richards D., Caldwell H.P., Go H., Impact of social media on the health of children and young people, "Journal of Paediatrics and Child Health" 2015, No. 51.

Sherman L.E., Michikyan M., Greenfield P.M., The effects of text, audio, video, and in-person communication on bonding between friends, "Cyberpsychology: Journal of Psychosocial Research on Cyberspace” 2013, No. 7(2).

Siibak A., Constructing the Self through the Photo selection - Visual Impression Management on Social Networking Websites, "Cyberpsychology: Journal of Psychosocial Research on Cyberspace" 2009, No. 3(1).

Sitko-Dominik M., Przynależność generacyjna, płeć psychologiczna, postawy wobec miłości a style użytkowania Facebooka przez młodych dorosłych, „Polskie Forum Psychologiczne” 2020, nr 25(2).

Śliwak J., Zarosińska D., Wysocka M., Partyka J., Poziom samooceny u osób korzystających z różnych form internetu, „Studia Socialia Cracoviensia” 2017, nr 9(2).

Steijn W.M., A developmental perspective regarding the behaviour of adolescents, young adults, and adults on social network sites, "Cyberpsychology: Journal of Psychosocial Research on Cyberspace" 2014, No. 8(2).

Thomas A., Textual constructions of children's online identities, "CyberPsychology \& Behavior” 2000, No. 3(4). 
Trusewicz-Pasikowska M., Tożsamość wirtualna - droga do wyzwolenia czy zniewolenia?, [w:] A. Kampka, K. Masłowska, A. Pawłowska (red.), Co nas wyzwala, co nas zniewala? Młodzi o wolności, Wydawnictwo SGGW, Warszawa 2018.

Valentine G., Holloway S., "Technophobia”: parents and children's fears about information and communication technologies and the transformation of culture and society, [w:] I. Hutchby, J. Moran-Ellis (red.), Children, technology and culture: the impacts of technologies in children's everyday lives, Routledge, Londyn 2001.

Verduyn P., Ybarra O., Résibois M., Jonides J., Kross E., Do Social Network Sites Enhance or Undermine Subjective Well-Being? A Critical Review, "Social Issues and Policy Review" 2017, No. 11(1).

Von Soest T., Wichstrøm L., Kvalem I.L., The development of global and domain-specific self-esteem from age 13 to 31, "Journal of Personality and Social Psychology" 2016, No. 110(4).

Walrave M., Utz S., Schouten A.P., Heirman W., Editorial: The state of online self-disclosure in an era of commodified privacy, "Cyberpsychology: Journal of Psychosocial Research on Cyberspace" 2016, No. 10(1).

Wang Z., Tchernev J.M., Solloway T., A dynamic longitudinal examination of social media use, needs, and gratifications among college students, "Computers in Human Behavior" 2012, No. 28(5).

Wichstrøm L., von Soest T., Reciprocal relations between body satisfaction and self-esteem: A large 13-year prospective study of adolescents, "Journal of Adolescence" 2016, No. 47.

Yau J.C., Reich S.M., "It's Just a Lot of Work": Adolescents' Self-Presentation Norms and Practices on Facebook and Instagram, "Journal of Research on Adolescence" 2018, No. 29(1).

\title{
The use of social media and its impact on the functioning of adolescents and young adults - an outline of the problem
}

\begin{abstract}
The aim of this paper is to present selected findings and an outline of research on the relationship between social media and adolescents and young adults. The paper focuses on three aspects of interest to, among others, cyberpsychology, i.e. the issue of gender and age differences in the use of social media, their impact on identity formation and the relationship between the user, social media and self-esteem. The cited studies show the dynamic of gendered changes in the way of using social media, whereby in the early days of the formation of the Internet it was boys who used it more to communicate with others, and today this relationship looks different. Research on identity focuses on the possibility of studying its formation and taking into account some specific aspects of it. Conclusions from research on self-esteem are inconclusive and mainly correlational, thus further research in this area is needed.
\end{abstract}

Keywords: cyberpsychology, identity, self-esteem, social media, adolescents, young adults 


\section{About the Author}

Piotr Klimczyk - Master of psychology, an assistant at Stefan Batory State University. Practitioner, psychologist at Maria Sklodowska-Curie’s Elementary School in Skierniewice. His academic research focuses on narrative psychology, cyberpsychology, and the psychology of education. 